\title{
A New Proposal for Vertical Extrapolation of Offshore Wind Speed and an Assessment of offshore Wind Energy Potential for the Hibikinada Area, Kitakyushu, Japan
}

\author{
Takanori Uchida \\ Research Institute for Applied Mechanics, Kyushu University, Kasuga-shi, Japan \\ Email: takanori@riam.kyushu-u.ac.jp
}

How to cite this paper: Uchida, T. (2018) A New Proposal for Vertical Extrapolation of Offshore Wind Speed and an Assessment of Offshore Wind Energy Potential for the Hibikinada Area, Kitakyushu, Japan. Energy and Power Engineering, 10, 154-164. https://doi.org/10.4236/epe.2018.104011

Received: March 6, 2018

Accepted: April 27, 2018

Published: April 30, 2018

Copyright ( 2018 by author and Scientific Research Publishing Inc. This work is licensed under the Creative Commons Attribution International License (CC BY 4.0).

http://creativecommons.org/licenses/by/4.0/

\begin{abstract}
The author's research group has been conducting research on applications of various meteorological Grid Point Value (GPV) data offered by the Japan Meteorological Agency (JMA) to the field of wind power generation. In particular, the group's research has been focusing on the following areas: 1) the use of GPV data from the JMA Meso-Scale Model (MSM-S; horizontal resolution: $5 \mathrm{~km}$ ) and the JMA Local Forecast Model (LFM-S; horizontal resolution: $2 \mathrm{~km}$ ), and 2) examinations of the prediction accuracy of local wind assessment with the use of these data. In both the MSM-S and the LFM-S, grid points are fixed at $10 \mathrm{~m}$ above the sea (ground) surface. The purpose of the present study is to establish a method in which the values of the MSM-S and LFM-S wind speed data from the $10 \mathrm{~m}$ height are used as the reference wind speed and are, using a power law, vertically extrapolated to 80 to $90 \mathrm{~m}$ heights, typical hub-heights of offshore wind turbines. For this purpose, the present study examined time-averaged vertical profiles of wind speed over the ocean based on the MSM-S data and in-situ data in the Hibikinada area, Kitakyushu City, Fukuoka Prefecture, Japan. As a result, it was revealed that a strong wind shear existed close to the sea surface, between the 10 and $30 \mathrm{~m}$ heights. In order to address the above-mentioned wind shear, a two-step vertical extrapolation method was proposed in the present study. In this method, two values of $\mathrm{N}$, specifically for low and high altitudes (below and above approximately 30 $\mathrm{m}$, respectively), were calculated and used. The data were created for the five years between 2012 and 2016. Similarly to previous analyses, the analysis of the created data set indicated that the potential of offshore wind power generation in the Hibikinada area, Kitakyushu City is quite high.
\end{abstract}




\section{Keywords}

Offshore Wind Energy, Weather GPV Data, Vertical Extrapolation Method, Power Law

\section{Introduction}

In recent years, offshore, as well as onshore, wind power generation has received attention, and many large-scale offshore wind farms have been constructed, mainly in Europe. In contrast, Japan falls significantly behind Europe in the field of offshore wind power generation as is the case for onshore wind power generation. However, Japan is a major maritime country with the world's sixth largest area of territorial waters and exclusive economic zone combined (approx. 4.47 million $\cdot \mathrm{m}^{2}$ ). Thus, Japan is favored with a high potential for offshore wind power generation. The 2014 Strategic Energy Plan states "In the mid- to long-term, further introduction of offshore wind power is indispensable for Japan where the potential of onshore wind power is limited." Thus, offshore wind power generation is expected to further increase in Japan. The Japan Wind Power Association (JWPA) has projected that offshore wind power generation will be installed on a large scale and that the cumulative installation goals for offshore wind power generation in Japan are 9.6 million and 37 million kW for 2030 and 2050, respectively.

As is the case for onshore wind power operation, a prior detailed assessment of the economic viability, risks, and other factors of offshore wind power operation at each site is necessary. In particular, accurate wind assessment is one of the most important issues to be examined since wind turbines are designed and the optimal deployment plan for wind turbines is created with the use of the results of the wind assessment. For wind assessment over the ocean, a vertical extrapolation procedure is generally required to extrapolate observed wind data to the wind turbine hub-height. When no numerical simulations are used, it is common to extrapolate wind speed with an empirical power law.

The author's research group has been conducting research to apply various meteorological Grid Point Value (GPV) data provided by the Japan Meteorological Agency (JMA) to the field of wind power generation. The group's research has focused especially on the following areas: 1) the use of GPV data from the JMA Meso-Scale Model (MSM-S; horizontal resolution: $5 \mathrm{~km}$ ) and the JMA Local Forecast Model (LFM-S; horizontal resolution: $2 \mathrm{~km}$ ), and 2) examinations of the prediction accuracy of local wind assessment with the use of these data [1] [2]. In both the MSM-S and the LFM-S, grid points are fixed at $10 \mathrm{~m}$ above the sea (ground) surface.

The present study points out issues that arise when vertically extrapolating wind speed data for 80 - $90 \mathrm{~m}$ heights, which are typical hub-heights for offshore wind turbines with a commonly-used empirical power law and the wind speed at 
the $10 \mathrm{~m}$ height from the MSM-S and LFM-S data as the reference wind speed. The present study also proposes a new method for vertically extrapolating wind speed close to the sea surface. Finally, the present study investigates the characteristics of offshore wind in the Hibikinada Area, Kitakushu City, Fukuoka Prefecture, Japan and makes preliminary economic estimates for offshore wind power generation in this area (Figure 1 and Figure 2).

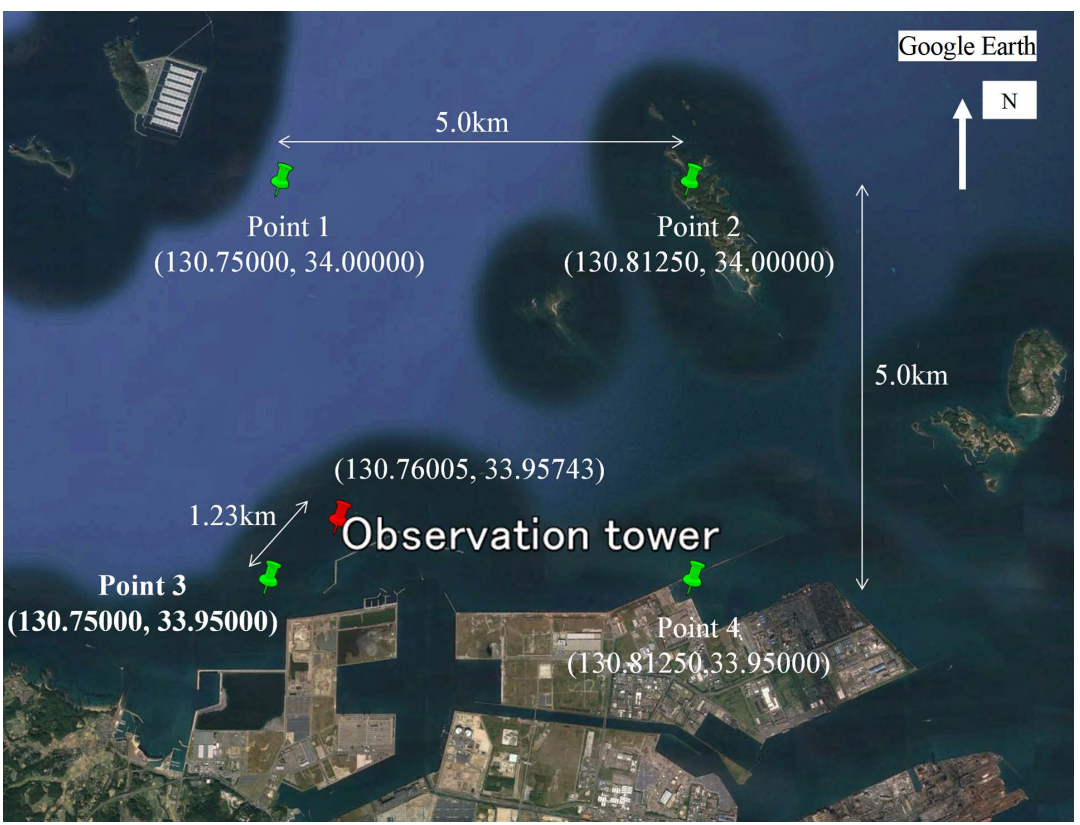

Figure 1. Locations of the observation tower (operated by NEDO) and grid points at which the MSM-S data values (10 m height) are available.

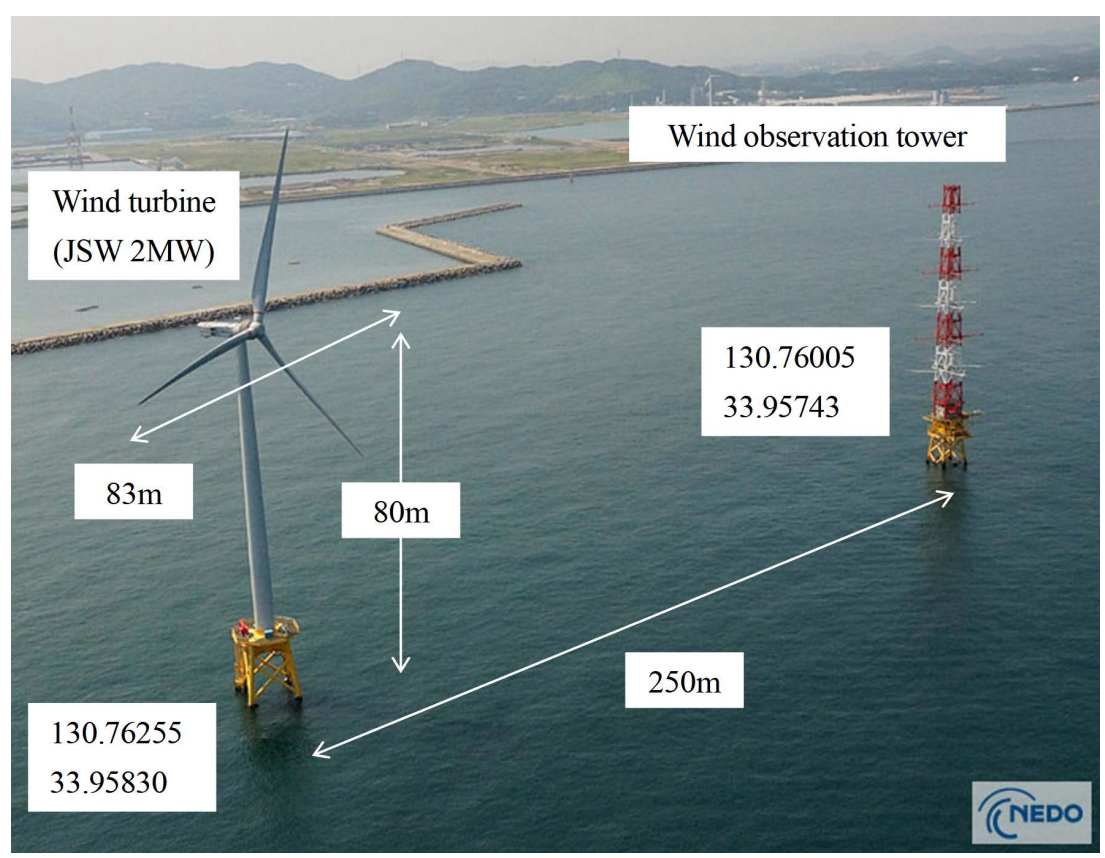

Figure 2. Photo of the wind observation tower and a wind turbine offshore of Kitakyushu City, Fukuoka Prefecture available. 


\section{Empirical Study Site}

In fiscal 2009, the New Energy and Industrial Technology Development Organization (NEDO) began conducting projects to deploy, in coastal waters, wind observation towers and offshore bottom-mounted wind turbines that would be operated for wind power generation. The two sites chosen are offshore of Choushi City, Chiba Prefecture and Kitakyushu City, Fukuoka Prefecture. The offshore wind turbines have been in operation at the sites since March 2013 (Choushi City) and June 2013 (Kitakyushu City), and empirical studies have been conducted at these sites (http://www.nedo.go.jp/fuusha/index.html).

On March 23, 2016, some of the achievements from empirical studies of bottom-mounted wind turbines from various areas including those offshore of Choushi City and Kitakyushu City in the above-mentioned project were released to the public (http://www.nedo.go.jp/news/press/AA5_100539.html).

In the present study, several investigations are conducted with the use of wind data from the site offshore of Kitakyushu City [3] [4], and preliminary economic estimates for offshore wind power generation are made for this site.

\section{Results and Discussions}

The purpose of the present study is to establish a method to estimate (by vertical extrapolation), with high accuracy, the wind speed at 80 to $90 \mathrm{~m}$ heights, typical hub-heights of offshore wind turbines. In this method, a commonly used empirical power law is employed, and the $10 \mathrm{~m}$ wind speeds from the MSM-S and LFM-S data are used as the reference wind speed.

Figure 1 shows the positional relationship between the offshore wind observation tower and the locations for which the MSM-S data (10 m height) are acquired, for the site offshore of Kitakyushu City. As shown in this figure, the MSM-S data from Point 3 were acquired at the grid point closest to the offshore wind observation tower at this site. Thus, for the data analysis, wind speed from the MSM-S data (10 m height, hourly-averaged data) from Point 3 are treated as the $10 \mathrm{~m}$ height wind speed of the wind observation tower. Readers are referred to previous literature [1] [2] for the prediction accuracy and other details of the hourly-averaged MSM-S data at the $10 \mathrm{~m}$ height. In the present study, to match with the availability of the wind observation tower data, the analysis period is set to an 11 month period between Oct. 1, 2012 and Aug. 31, 2013 [3] [4]. As for the wind observation tower data, $10 \mathrm{~min}$ averaged values of wind data that were acquired by three-cup anemometers and wind vanes at six heights of $31.6 \mathrm{~m}, 41.6$ m, $51.6 \mathrm{~m}, 61.6 \mathrm{~m}, 71.6 \mathrm{~m}$, and $81.6 \mathrm{~m}$ above the sea surface are analyzed [3] [4].

Figure 3 shows the vertical profile of the wind speed data (in-situ data) averaged over the 11 months between Oct. 1, 2012 and Aug. 31, 2013 (symbol: •). The value of $\mathrm{N}$ that is calculated from Equation (1) based on these data is 10.1 [3] [4]. Figure 3 also shows the MSM-S wind speed data (10 $\mathrm{m}$ height, symbol:

-) averaged over the same 11 month period.

The red dotted line in Figure 3 shows the vertical profile of the predicted 


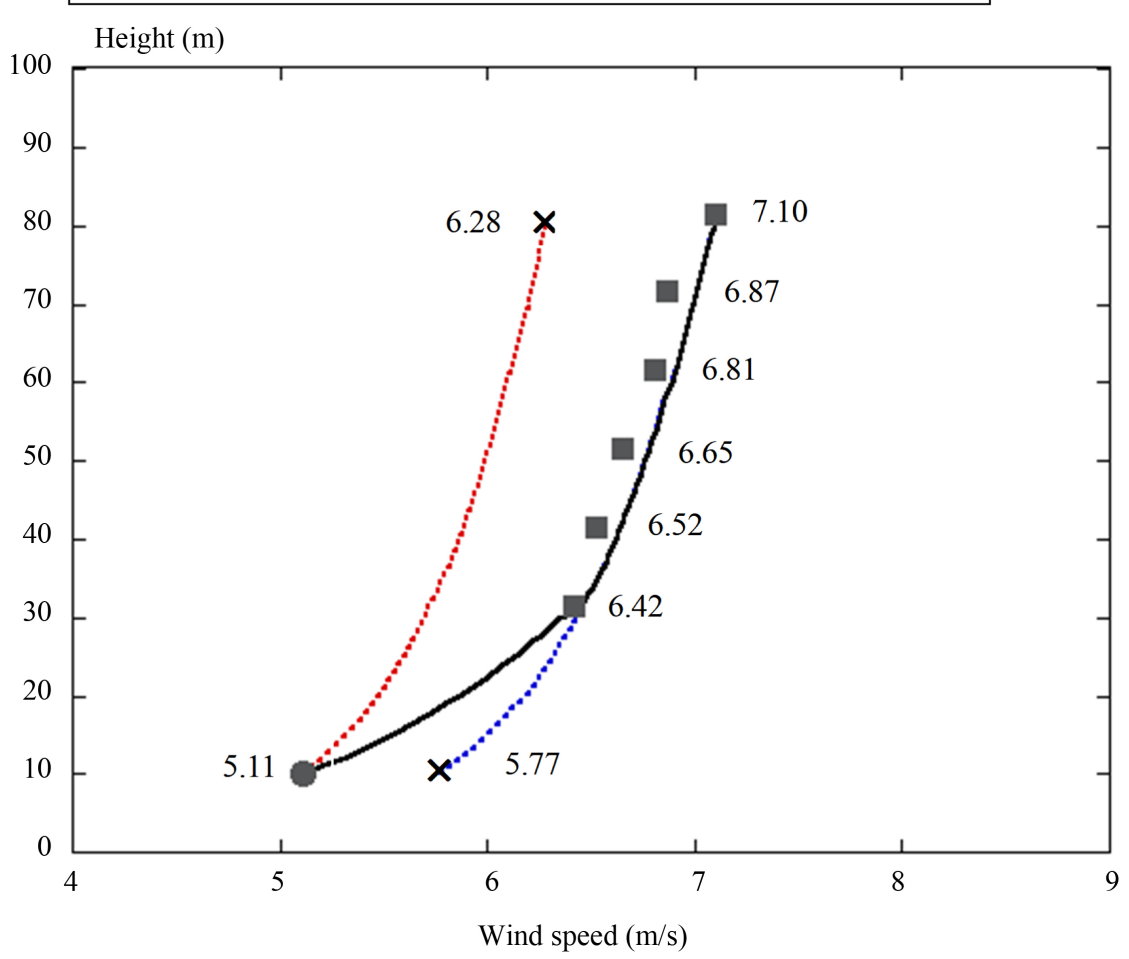

Figure 3. Vertical profiles of wind speed from three power law-based methods: the newly proposed method (black line) and two other methods.

time-averaged wind speed up to the height of $81.6 \mathrm{~m}$ above the sea surface. The profile was calculated using Equation (1) and the time-averaged $10 \mathrm{~m}$ wind speed from the MSM-S wind data $(5.11 \mathrm{~m} / \mathrm{s})$ as the reference wind speed. For the value of $\mathrm{N}$ in Equation (1), the above-mentioned value of $\mathrm{N}=10.1$, which was evaluated from the in-situ wind speed data, was used. An examination of the profile reveals that the time-averaged wind speed is $6.28 \mathrm{~m} / \mathrm{s}$ at the height of 81.6 $\mathrm{m}$, which is an underestimate of approximately $0.8 \mathrm{~m} / \mathrm{s}$ with respect to the time-averaged value of the in-situ wind speed data $(7.10 \mathrm{~m} / \mathrm{s})$ from the same height.

The blue dotted line in Figure 3 shows the vertical profile of the predicted time-averaged wind speed down to $10 \mathrm{~m}$ above the sea surface. The values in the profile were predicted using Equation (1) with the time-averaged values of the in-situ wind speed from the $81.6 \mathrm{~m}$ height $(7.10 \mathrm{~m} / \mathrm{s})$ as the reference wind speed. For the value of $\mathrm{N}$, the value that was evaluated from the in-situ wind speed data was used $(\mathrm{N}=10.1)$. At the $10 \mathrm{~m}$ height, the predicted value of the 
time-averaged wind speed is $5.77 \mathrm{~m} / \mathrm{s}$, which is an overestimate of approximately $0.7 \mathrm{~m} / \mathrm{s}$ with respect to the time-averaged wind speed from the MSM-S data at the same height $(5.11 \mathrm{~m} / \mathrm{s})$.

The results above suggest that strong wind shear exists over the sea at heights of 10 to $30 \mathrm{~m}$, that is, close to the surface. In order to address this issue, a two-step vertical extrapolation method is proposed in the present study. The specific procedure for the two-step vertical extrapolation method will be described in the following subsections.

\subsection{Vertical Extrapolation Method for Low Altitudes (Approximately $30 \mathrm{~m}$ or Lower) (Step 1)}

A value of $\mathrm{N}(=5.04)$ is derived from Equation (1) with the use of the MSM-S wind speed data from the $10 \mathrm{~m}$ height and the observed wind speed data from the $31.6 \mathrm{~m}$ height. Specifically, the time-averaged wind data from the period of analysis are used for determining the value of $\mathrm{N}$. This value of $\mathrm{N}$ is used to predict the vertical profile of the wind speed between the heights of $10 \mathrm{~m}$ and 31.6 $\mathrm{m}$. For this prediction, the $10 \mathrm{~m}$ wind speeds from the MSM-S data are used as the reference wind speed.

$\underline{\underline{\text { Power law }}}$

$$
U\left(h_{2}\right)=U\left(h_{1}\right) \cdot\left(\frac{h_{2}}{h_{1}}\right)^{\frac{1}{N}}
$$

\subsection{Vertical Extrapolation Method for High Altitudes (Approximately $30 \mathrm{~m}$ or Higher) (Step 2)}

A value of $\mathrm{N}(=10.1)$ is derived from Equation (1) with the use of observed wind speed data from the $31.6 \mathrm{~m}$ and $81.6 \mathrm{~m}$ heights. As in the previous step, the time-averaged wind data from the period of analysis are used for determining the value of $\mathrm{N}$. This value of $\mathrm{N}$ is used to predict the vertical profile of the wind speed between the heights of 31.6 and $81.6 \mathrm{~m}$. For this prediction, the observed wind speed data from the $31.6 \mathrm{~m}$ height are used as the reference wind speed.

\subsection{Results and Discussions: Vertical Extrapolation of Wind Speed Based on the Proposed Two-Step Vertical Extrapolation Method}

The power law was applied twice to predict the vertical profile of the time-averaged wind speed, which is shown as the black solid line in Figure 3. This profile was obtained using the two above-mentioned height-dependent values of $\mathrm{N}$, that is, 5.04 and 10.1 for the heights $10-31.6 \mathrm{~m}$ and the heights $31.6-81.6 \mathrm{~m}$, respectively. By applying the proposed wind speed vertical extrapolation method, it is now possible to vertically extrapolate the MSM-S and LFM-S wind speed data from the $10 \mathrm{~m}$ height to 80 to $90 \mathrm{~m}$ heights, i.e., typical hub-heights of offshore wind turbines, while employing the MSM-S and LFM-S wind speed data from the $10 \mathrm{~m}$ height as the reference wind speed. 
In the present study, a time-series data set (hourly-averaged wind speed and direction) was created for the $80 \mathrm{~m}$ height at the location of the wind observation tower using the proposed two-step vertical extrapolation method. For the reference wind speed, MSM-S wind speed data from the $10 \mathrm{~m}$ height at Point 3 (Figure 1) were used. For the pair of $\mathrm{N}$ values, 5.04 and 10.1 were used. The data set was created for the five years between 2012 and 2016. Hereafter, the results of analyses of this data set will be shown.

Figure 4 shows the wind rose of the wind direction from the created data set. The prevailing wind directions at this site are WNW and ESE, which correspond to winds blowing from the sea and land, respectively. In the five years between 2012 and 2016, the prevailing wind directions did not change in general, and wind characteristics including the occurrence frequency of the other wind directions remained nearly the same over the course of the five years.

Figure 5 shows the monthly and annual average wind speeds for the $80 \mathrm{~m}$ height for the five years between 2012 and 2016. In all five years, the monthly average wind speed is approximately $5-6 \mathrm{~m} / \mathrm{s}$ in the summer period between May and August. However, strong monthly average wind speeds of $7-9 \mathrm{~m} / \mathrm{s}$ occurred in the fall to spring period between September and April. An examination of the temporal variation of the annual average wind speed between 2012 and 2016 reveals that the value of the annual average wind speed is slightly lower in 2016 than in the other years. However, the annual average wind speed for 2016 is approximately $7 \mathrm{~m} / \mathrm{s}$ as indicated on the right of Figure 5 . These results indicate that the site offshore of Kitakyushu City is favorable for implementing

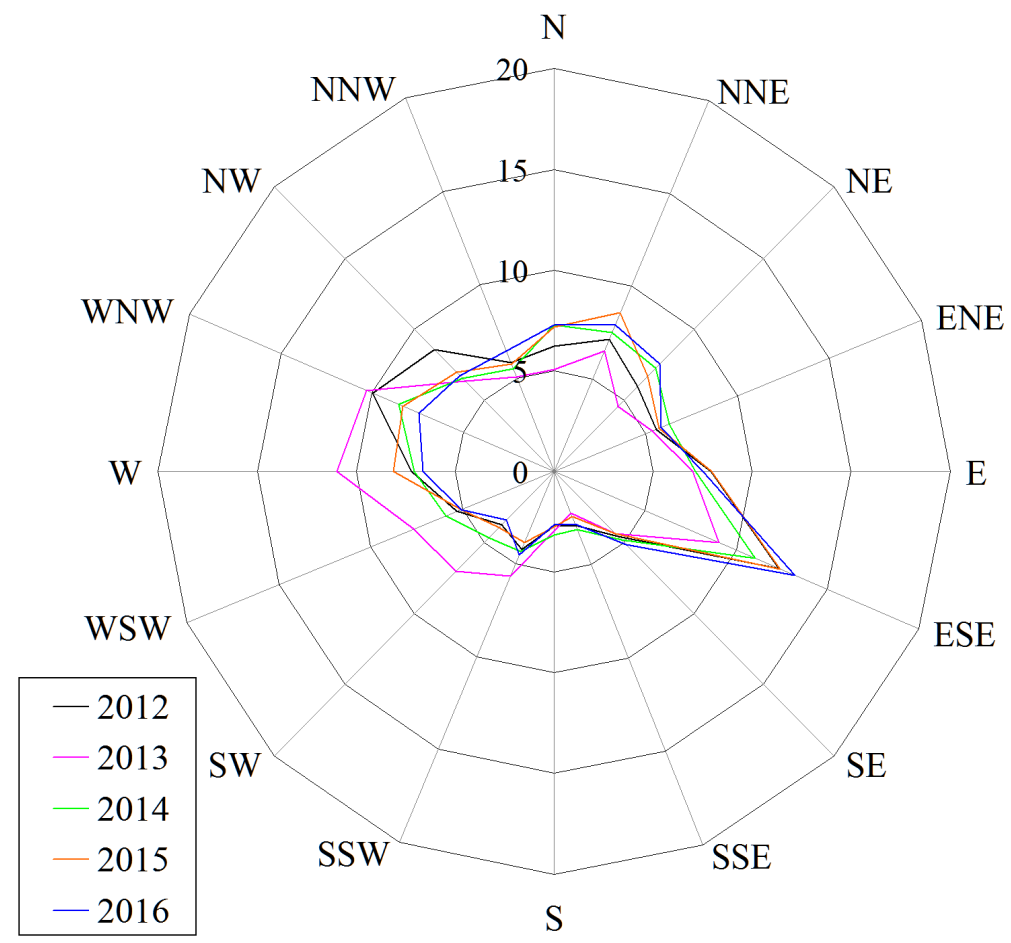

Figure 4. Occurrence frequency of wind direction (\%) at a height of $80 \mathrm{~m}$. 


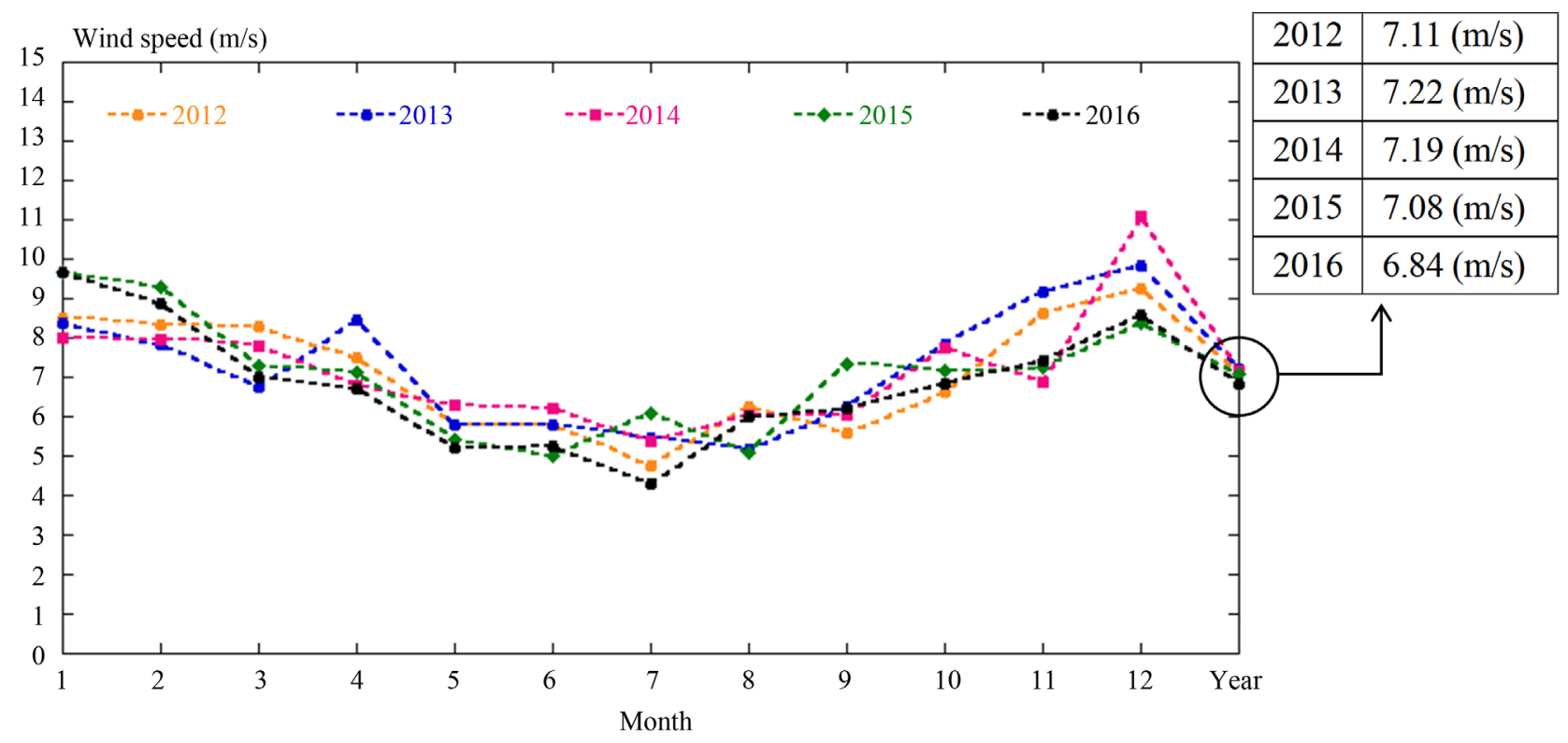

Figure 5. Wind speed $(\mathrm{m} / \mathrm{s})$ at a height of $80 \mathrm{~m}$.

offshore wind power generation.

Figure 6 shows the occurrence frequency of wind speed classes at the $80 \mathrm{~m}$ height from the five years between 2012 and 2016. As was the case for Figure 4 and Figure 5, little temporal variation exists in the occurrence frequency of wind speed classes, indicating nearly identical wind characteristics in these five years.

With the use of the time-series wind data set described and analyzed above, the present study also made economic estimates for the case in which a large 5 MW offshore wind turbine were to be deployed. Figure 7 shows the power curve for this wind turbine.

Figure 8 shows the values of the energy production that were calculated for each month. Figure 9 shows the values of the capacity factor that were calculated for each month and year. As is the case for the wind speed in Figure 5, the monthly values of the energy production and capacity factor are generally low in the summer period between May and August, but favorable for wind power generation in the fall to spring period between September and April. An examination of the values of the annual capacity factor in Figure 9 (the values on the right of Figure 9) reveals that although the value from 2016 is slightly below $30 \%$, those from 2012 to 2015 exceed $30 \%$.

\section{Conclusions}

The author's research group has been conducting research on applications of various meteorological Grid Point Value (GPV) data offered by the Japan Meteorological Agency (JMA) to the field of wind power generation. In particular, the group's research has been focusing on the following areas: 1) the use of GPV data from the JMA Meso-Scale Model (MSM-S; horizontal resolution: $5 \mathrm{~km}$ ) and the JMA Local Forecast Model (LFM-S; horizontal resolution: $2 \mathrm{~km}$ ), and 2) 


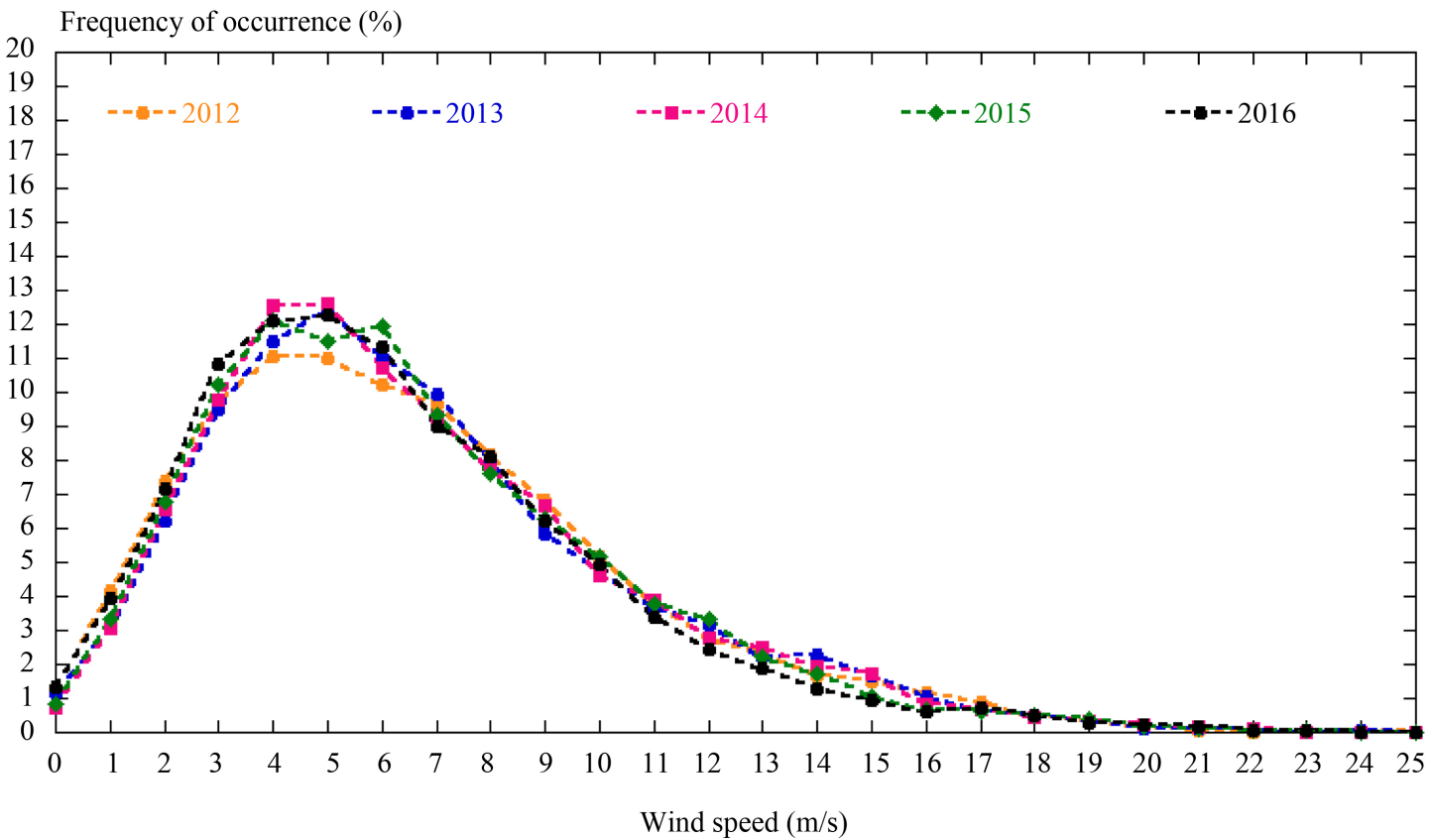

Figure 6. Occurrence frequency (\%) of wind speed at a height of $80 \mathrm{~m}$.

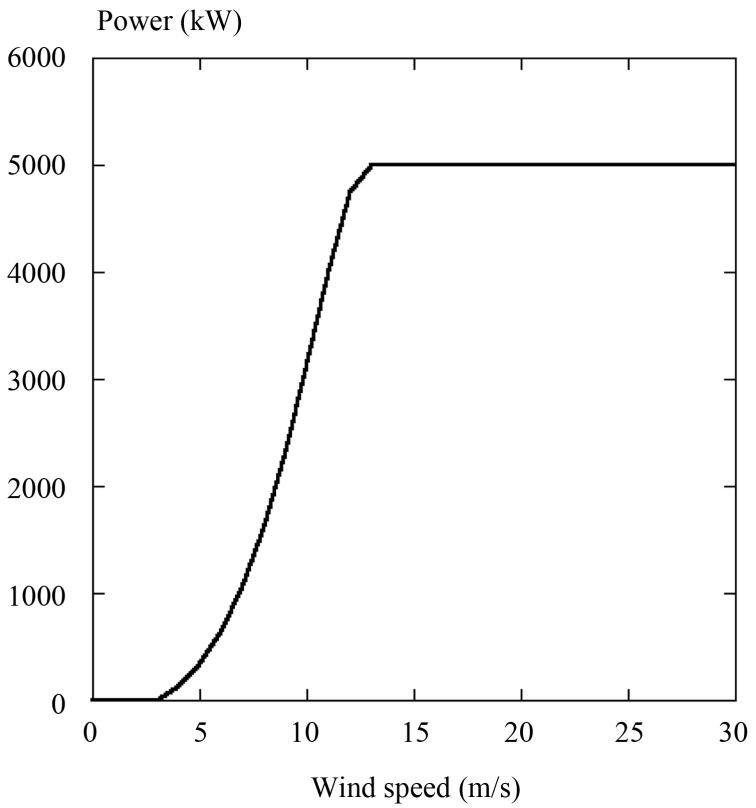

Figure 7. Power curve for the $5 \mathrm{MW}$ wind turbine.

examinations of the prediction accuracy of local wind assessment with the use of these data. In both the MSM-S and the LFM-S, grid points are fixed at $10 \mathrm{~m}$ above the sea (ground) surface.

The purpose of the present study is to establish a method in which the values of the MSM-S and LFM-S wind speed data from the $10 \mathrm{~m}$ height are used as the reference wind speed and are, using a power law, vertically extrapolated to 80 to $90 \mathrm{~m}$ heights, typical hub-heights of offshore wind turbines. 


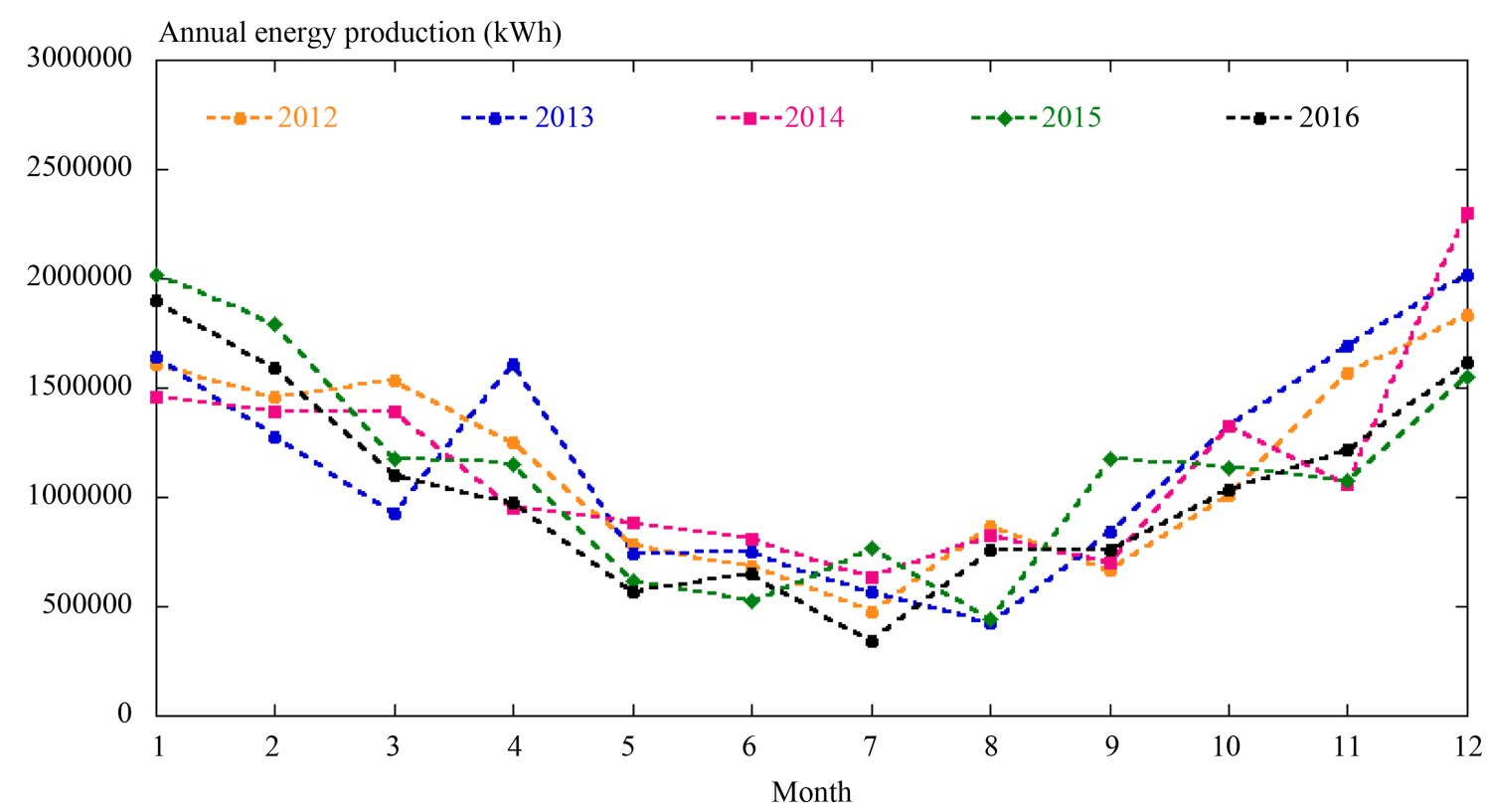

Figure 8. Annual energy production (kWh).

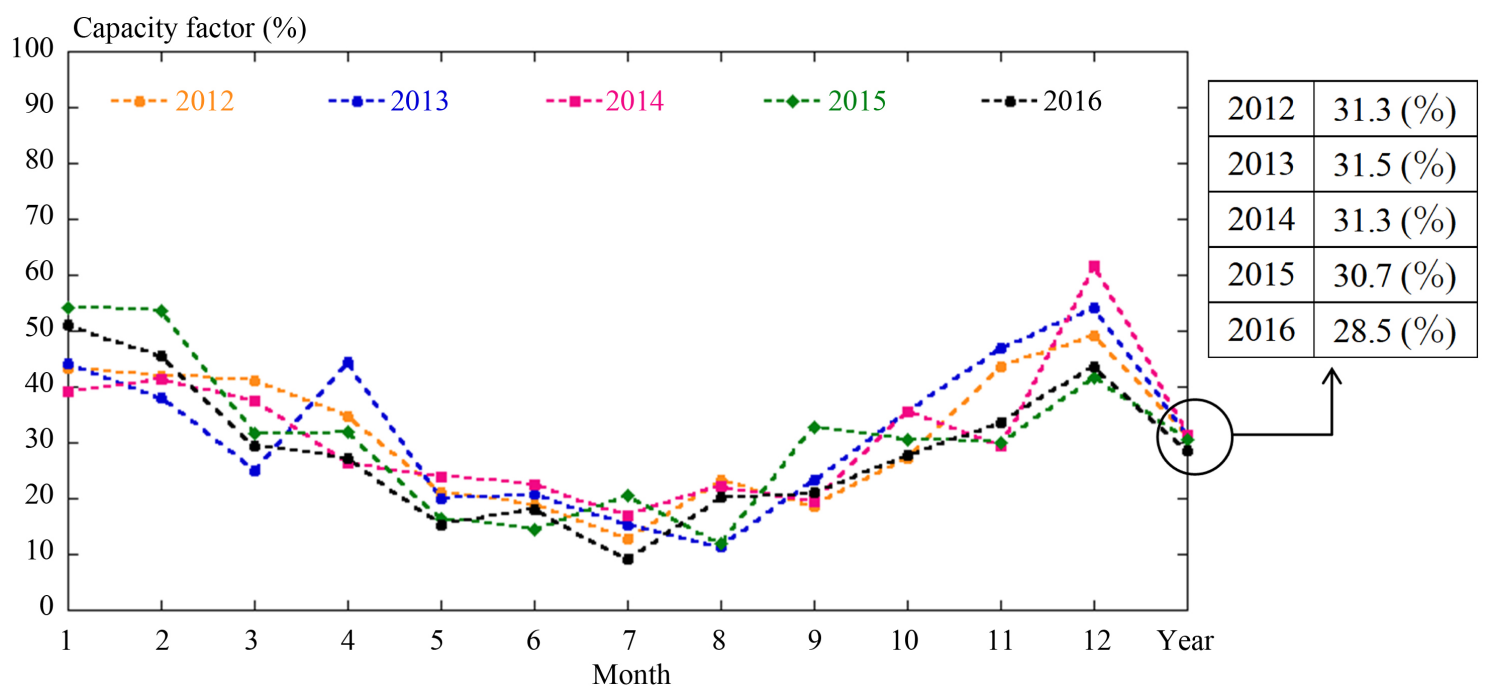

Figure 9. Capacity factor (\%).

For this purpose, the present study examined time-averaged vertical profiles of wind speed over the ocean based on the MSM-S data and in-situ data in the Hibikinada area, Kitakyushu City, Fukuoka Prefecture, Japan (MSM-S data: hourly-averaged data of wind speed and direction at $10 \mathrm{~m}$ above the sea surface; in-situ data: $10 \mathrm{~min}$ averaged data of wind speed and direction measured with three-cup anemometers and wind vanes at six heights above the sea surface, namely, $31.6 \mathrm{~m}, 41.6 \mathrm{~m}, 51.6 \mathrm{~m}, 61.6 \mathrm{~m}, 71.6 \mathrm{~m}$, and $81.6 \mathrm{~m}$ ).

As a result, it was revealed that a strong wind shear existed close to the sea surface, between the 10 and $30 \mathrm{~m}$ heights. Thus, with a direct application of the commonly used empirical power law and the $10 \mathrm{~m}$ height wind speed from the 
MSM-S and LFM-S data as the reference wind speed, the wind speed at the 80 to $90 \mathrm{~m}$ heights was underestimated by approximately $0.8 \mathrm{~m} / \mathrm{s}$ with respect to the wind speed measured in situ.

In order to address the above-mentioned wind shear, a two-step vertical extrapolation method was proposed in the present study. In this method, two values of $\mathrm{N}$, specifically for low and high altitudes (below and above approximately $30 \mathrm{~m}$, respectively), were calculated and used. Using the $10 \mathrm{~m}$ wind speed from the MSM-S and LFM-S data as the reference wind speed, the proposed method has enabled the $10 \mathrm{~m}$ wind speed to be vertically extrapolated to 80 to $90 \mathrm{~m}$ heights, typical hub-heights of offshore wind turbines.

Subsequently, with the use of the newly proposed two-step vertical extrapolation method and the two values of $\mathrm{N}(=5.04,10.1)$, a time-series of hourly-averaged wind speed and direction data was created for the $80 \mathrm{~m}$ height at the location of the offshore wind observation tower shown in Figure 2. The data were created for the five years between 2012 and 2016. Similarly to previous analyses, the analysis of the created data set indicated that the potential of offshore wind power generation in the Hibikinada area, Kitakyushu City is quite high.

\section{References}

[1] Uchida, T. and Kawashima, Y. (2014) Practical Use of Weather GPV Data to Wind Power Field in the Coastal Area in the Case of the Wind Farm in the Kagoshima Prefecture. Reports of Research Institute for Applied Mechanics, Kyushu University, No. 147, 15-29. (In Japanese) https://doi.org/10.15017/1526215

[2] Uchida, T. and Kawashima, Y. (2014) Practical Use of Weather GPV Data to Wind Power Field in the Mountainous Area in the Case of the Asokurumagaeri Wind Farm. Reports of Research Institute for Applied Mechanics, Kyushu University, No. 147, 31-43. (In Japanese) https://doi.org/10.15017/1526216

[3] Yoshimura, Y. (2013) Present Situation of Offshore Wind Power Generation System Providing Research in Kitakyushu City. Proceedings of 35 th Wind Energy Symposium, 13 November 2013, Tokyo, 478-481. (In Japanese)

[4] Aoki, I. and Yoshimura, Y. (2013) Offshore Wind Analysis by Offshore Wind Condition Sysytem Providing Research in Kitakyushu City. Proceedings of 35 th Wind Energy Symposium, 13 November 2013, Tokyo, 482-485. (In Japanese) 